\title{
Self-medication trend among the urban elderly - a cross-sectional, observational study
}

\author{
Arunava Biswas', Sukanta Sen', Agnik Pal' ${ }^{2}$ Joydip Das', Suvajit Das³, Santanu Kumar Tripathi \\ ${ }^{1} D M$ (Clinical Pharmacology) Post Doctoral Trainee, Department of Clinical \& Experimental Pharmacology, Calcutta School of Tropical \\ Medicine, 108, C.R. Avenue, Kolkata, India, ${ }^{2} \mathrm{MD}$ (Pharmacology) Post Graduate Trainee, Department of Clinical \& Experimental \\ Pharmacology, Calcutta School of Tropical Medicine, 108, C.R. Avenue, Kolkata, India, ${ }^{3}$ Assistant Professor, ICARE Institute of Medical \\ Sciences and Research, Haldia, West Bengal, India, ${ }^{4}$ DM (Clinical Pharmacology) Prof \& HOD, Department of Clinical \& Experimental \\ Pharmacology, Calcutta School of Tropical Medicine, 108, C.R. Avenue, Kolkata
}

\section{A B S TR A C T}

Objective: To describe and analyze the demographic and pharmacological characteristics of self-medication trends among a geriatric urban population in a community. Materials and Methods: This structured interview-based, cross-sectional survey was conducted among elderly subjects of either sex in an urban community, who visited two pre-identified, retail pharmacies in a sub-urban locality, for procuring sundry medicinal products of their choice, without a valid prescription. Institutional ethics approval was duly obtained. Respondents $(n=108)$ readily shared the information as sought regarding the encounter. The data were captured by trained field staff in a pre-designed data sheet, maintaining full confidentiality. Results: The subjects $(n=108)$ were predominantly $(64.81 \%)$ male, with an average age of 65.95 years. The subjects mostly retired from job. Only $21.29 \%$ of them asked for particular brands, whereas just $5.55 \%$ subjects asked for a generic product. Majority of the subjects $(73.14 \%)$ sought for medical help and received it from the dispenser at the counter. Antibiotics, on most occasions, were dispensed for inappropriate indication and duration. On an average, the cost of the medicines procured in a single encounter by the employed and unemployed were Rs 51.86 and Rs 21.86 respectively. Conclusion: Self-medication trends in elderly are a disturbing problem that needs to be carefully addressed. Pilot study such as the present one is easy to carry out, and can rapidly yield information about the true nature of self medication trends among the elderly. This can help in designing effective and appropriately targeted interventions in the future.

Key words: Self medication, Urban, Elderly people
Access this article online Website:

http://nepjol.info/index.php/AJMS DOI: 10.3126/ajms.v6i5.11725

\section{INTRODUCTION}

Self medication could be defined as taking drugs without the advice and monitoring of a physician. ${ }^{1}$ Such practice among the elderly can sometimes be a concern, especially if remedies taken without prescription interact with prescribed medications or if they produce adverse effects. The importance of self-medication as a phenomenon has attracted the interest of health professionals including physicians and policy-makers, especially when drugs become deregulated and change from prescription status to be sold over-the-counter (OTC). Generally, it is accepted that self-medication has an important role in the care of minor illness. ${ }^{2,3}$ Many possible benefits ${ }^{4,5}$ and risks ${ }^{6,7}$ have been attributed to increased self-medication among the public. The practice of self-medication is common worldwide in both developed and developing countries ${ }^{8,9}$ and may even be more common than the use of prescribed medication. ${ }^{10} \mathrm{On}$ the other hand indulgence in practice of such unsupervised treatment may cause a great health concern especially to the vulnerable population. Polypharmacy of prescribed medicines is more prevalent among older people and increases the potential for drug interactions when OTC medicines are used. There are no as such published data 
on the drug seeking behavior of the elderly in the Indian population. Since they are potential vulnerable group of people often suffering from multiple disease ailments, the self medication behavior in the perspective of OTC is a big challenge. So far there is no such list of OTC drug formulary in our country and dispensation of almost every medicine is possible on subject on mere request. Therefore this study was undertaken to describe and analyze the demographic and pharmacological characteristics of self-medication among a geriatric urban population in a community.

\section{MATERIALS AND METHODS}

A structured interviewed based, observational, descriptive, cross sectional, community based pilot study was conducted by the Department of Clinical and Experimental Pharmacology, Calcutta School of Tropical Medicine, Kolkata for a period of 3 months with prior approval from the institutional ethics committee. Initially, the dedicated field staffs were trained appropriately and two community pharmacy stores situated in an urban area of Kolkata were identified after proper consent and permission taken from the respective shop owners. Elderly subject $(>60 \mathrm{yrs})$ of either sex approaching either of these two designated pharmacy stores to purchase allopathic medicine(s) without any valid prescription were targeted. Dedicated field staffs approached the subjects and explained the study protocol. Positive respondent signed the ICF and were enrolled in the study. Relevant data collected in predesigned pretested data capturing sheet maintaining confidentiality of the subjects. The collected data were processed at the study centre on day to day basis. Finally the collected data were analyzed on the basis of mean and percentage at the study centre using Microsoft Excel 2007.

\section{RESULTS}

The subjects $(\mathrm{n}=108)$ were predominantly $(64.81 \%)$ male, with an average age of 65.95 years. The subjects were mostly retired from job. The oral products both solid and liquid dosage forms were dispensed most frequently from over the counter of the pharmacy stores [Figure 1].

Only $21.29 \%$ of them asked for particular brands, whereas just $5.55 \%$ subjects asked for a generic product. Fever, headache, pain and spasms were some of the most common symptoms narrated over the counter by the subjects. Ofloxacin plus ornidazole as fixed dose combination was the most commonly dispensed antibiotics followed by metronodazole and azithromycin [Figure 2].

Antibiotics, on most occasions (34.25\%), were dispensed for an inappropriate duration except azithromycin and levofloxacin [Figure 3]. Among the analgesics paracetamol was dispensed most commonly followed by combination

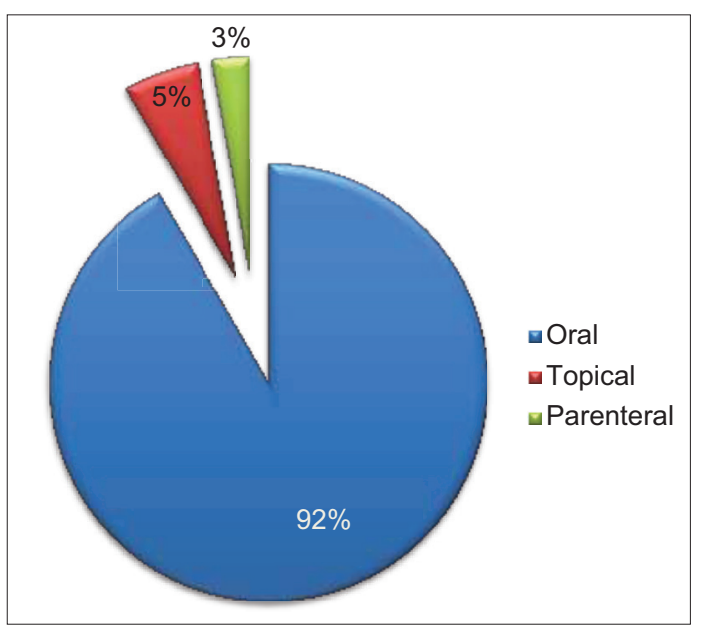

Figure 1: Types of products dispensed over the pharmacy counter

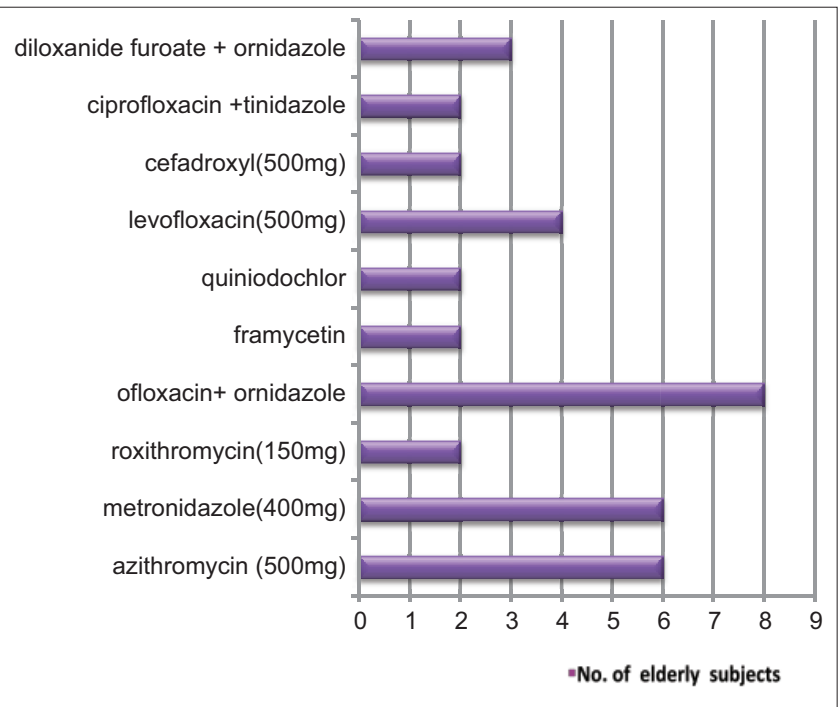

Figure 2: Types of antibiotics dispensed at the pharmacy stores

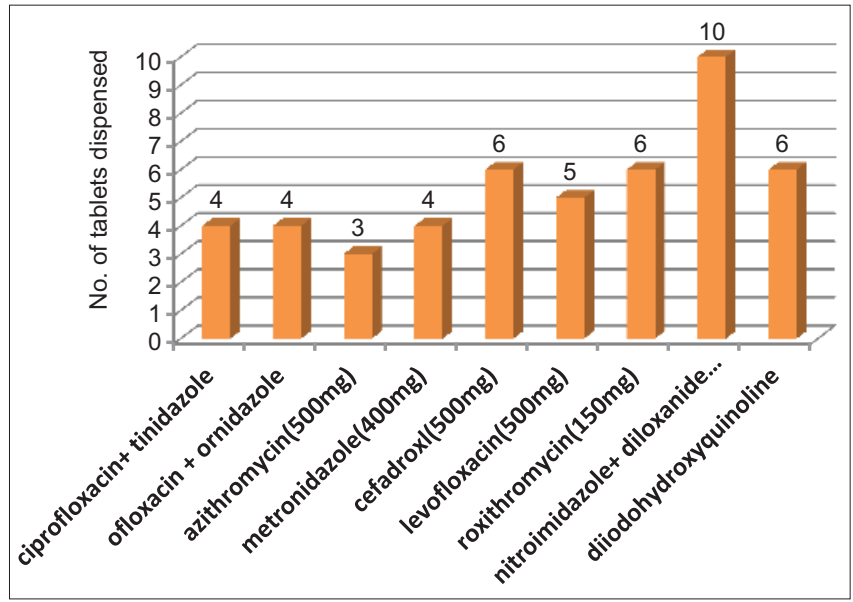

Figure 3: Antibiotic dispensing patterns among the subjects 


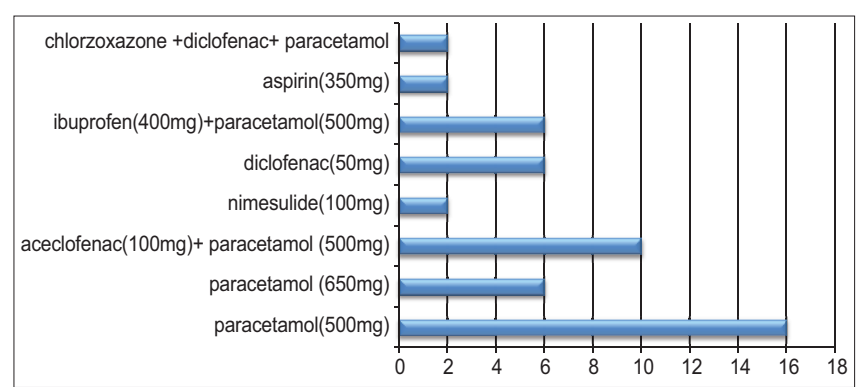

Figure 4: Types of analgesics dispensed

of paracetamol plus aceclofenac [Figure 4]. There was inadvertent use of analgesic of different types (46.29\%) with co administration of an anti ulcer agent in most of the occasions. On an average, the cost of the medicines procured in a single encounter by the employed and unemployed were Rs 51.86 and Rs 21.86 respectively.

\section{DISCUSSION}

This study focused on a targeted population, namely elderly people aged 60 and older in a urban community in Kolkata and sought to provide an insight into the selfmedication practices of the elderly from over the counter perspective. Majority of the subjects (73.14\%) sought for medical help and received it from the dispenser at the counter. Almost in every third patient received some antibiotics for in appropriate duration and probably for inappropriate indication which is an alarming concern from the drug resistance perspective especially for such vulnerable population. Similarly analgesics mainly NSAIDs were dispensed to almost every alternate patient although under the coverage of an antiulcer agent in most of the occasions. The study made an attempt to explore and analyze a potential knowledge gap in the community especially among the vulnerable population e.g. elderly towards a dangerous practice of self medication in the absence of any national formulary on OTC products in India.

\section{LIMITATIONS}

The study has certain limitations like the cross sectional design precludes the possibility of treatment adherence, follow up and outcome analysis, the study did not accommodate the opportunity of interviewing the pharmacist at the counter which could have important bearing on the observation, the trend of alternative medication usage with its potential impact of allopathic drugs and import of self medication practice in general and the potential for adverse drug interactions was not considered in this study.

\section{CONCLUSION:}

Self-medication trends in the elderly are certainly prevalent among the urban elderly. This small scale study shall help us in planning bigger longitudinal study addressing the knowledge gaps existing in the perspective, in our future endeavor.

\section{ACKNOWLEDGEMENT}

The authors declare that there is no conflict of interests. The authors acknowledges the field staffs engaged in this study for their untiringly job in collection of data.

\section{REFERENCES}

1. Montastruc JL, Bagheri $\mathrm{H}$, Geraud $\mathrm{T}$ and Mestre ML. Pharmacovigilance of self medication. Therapie 1997; 52:105-110.

2. Guidelines for the medical assessment of drugs for use in selfmedication 1986. Copenhagen, World Health Organization Regional Office for Europe.

3. Hayran O, Karavus M and Aksayan S. Help-seeking behavior and self - medication of a population in an urban area in Turkey: cross sectional study. Croatian Medical Journal 2000; 41:327-332.

4. Yousef AM, Al- Bakri AG, Bustanji $Y$ and Wazaify M. Self medication patterns in Amman, Jordan. Pharmacy World and Science 2008; 30:24-30.

5. Awad Al, Eltayeb IB and Capps PA. Self-medication practices in Khartoum State, Sudan. European Journal of Clinical Pharmacology 2006; 62: 317- 324.

6. Hamel MJ, Odhacha A, Roberts JM and Deming MS. Malaria control in Bungoma District,Kenya: a survey of home treatment of children with fever, bed net use and attendance at antenatal clinics. Bulletin of the World Health Organization 2001; 79:1014-1023.

7. Promoting rational use of medicines: Core components. WHO policy perspectives on medicines. 2002; Geneva, World Health Organization, (WHO/EDM/2002.3).

8. Figueiras A, Caamaño F and Gestal Otero JJ. Sociodemographic factors related to self medication in Spain. European Journal of Epidemiology 2000; 16: 19-26.

9. Fuentes KA and Villa LZ. Analysis and quantification of self medication patterns of customers in community pharmacies in southern Chile. Pharmacy World and Science 2008; 30: 863-868.

10. Lam CL, Tse MH and Munro C. A survey on the use of self medication over a period of two weeks. Hong Kong Practitioner 1989; 11: 371-375.

\section{Authors Contribution:}

AB- Designed the study, performed the field work, analysed the data, drafted the manuscript, \& reviewed the manuscript; SS - Contributed to the study design;

AP - Assisted in data collection; JD - Assisted in data collection; SD - Reviewed the manuscript; SKT - Overall supervised the study.

Source of Support: Nil, Conflict of Interest: None declared. 